OPEN ACCESS

Edited by:

Nady Braidy,

University of New South Wales,

Australia

Reviewed by:

Amandine Grimm,

University of Basel, Switzerland

Antonina Luca,

University of Catania, Italy

*Correspondence:

Jamshed Arslan

jamshed.arslan@bhu.edu.pk;

jamshed.arslan@gmail.com

Received: 01 April 2020

Accepted: 01 July 2020

Published: 27 July 2020

Citation:

Arslan J, Jamshed H and Qureshi H (2020) Early Detection and Prevention of Alzheimer's Disease: Role of Oxidative Markers and

Natural Antioxidants. Front. Aging Neurosci. 12:231. doi: 10.3389/fnagi.2020.00231

\section{Early Detection and Prevention of Alzheimer's Disease: Role of Oxidative Markers and Natural Antioxidants}

\author{
Jamshed Arslan ${ }^{1 *}$, Humaira Jamshed ${ }^{2}$ and Humaira Qureshi ${ }^{2}$ \\ ${ }^{1}$ Department of Basic Medical Sciences, Faculty of Pharmacy, Barrett Hodgson University, Karachi, Pakistan, ${ }^{2}$ Department \\ of Integrated Sciences and Mathematics, Dhanani School of Science and Engineering, Habib University, Karachi, Pakistan
}

Oxidative stress (OS) contributes to Alzheimer's disease (AD) pathology. OS can be a result of increased reactive oxygen/nitrogen species, reduced antioxidants, oxidatively damaged molecules, and/or a combination of these factors. Scientific literature is scarce for the markers of OS-specific for detecting $A D$ at an early stage. The first aim of the current review is to provide an overview of the potential OS markers in the brain, cerebrospinal fluid (CSF), blood and/or urine that can be used for early diagnosis of human AD. The reason for exploring OS markers is that the proposed antioxidant therapies against $A D$ appear to start too late to be effective. The second aim is to evaluate the evidence for natural antioxidants currently proposed to prevent or treat AD symptoms. To address these two aims, we critically evaluated the studies on humans in which various OS markers for detecting $A D$ at an early stage were presented. Non-invasive OS markers that can detect mild cognitive impairment (MCl) and $A D$ at an early stage in humans with greater specificity and sensitivity are primarily related to lipid peroxidation. However, a combination of OS markers, family history, and other biochemical tests are needed to detect the disease early on. We also report that the long-term use of vitamins (vitamin $E$ as in almonds) and polyphenol-rich foods (curcumin/curcuminoids of turmeric, ginkgo biloba, epigallocatechin-3-gallate in green tea) seem justified for ameliorating AD symptoms. Future research on humans is warranted to justify the use of natural antioxidants.

Keywords: reactive oxygen species, mild cognitive impairment, lipid peroxidation, tocopherols, polyphenols

\section{INTRODUCTION}

Alzheimer's disease (AD) is the most common dementia of the elderly (Fattoretti et al., 2018). The discovery that memory decline often precedes other neuropathological signs of $\mathrm{AD}$ (Thomas et al., 2020) has ignited an interest in the pathology of $\mathrm{AD}$, especially the translational state between normal aging and $\mathrm{AD}$ called mild cognitive impairment (MCI). Oxidative stress (OS) underlies MCI (Cervellati et al., 2014a; Di Domenico et al., 2016) and neurodegenerative diseases including AD (Dong et al., 2018). Various antioxidants have been suggested to prevent or even cure AD (Boasquivis et al., 2018; Mohamed et al., 2018; Popli et al., 2018). Major biomarkers of oxidative 
damage in AD have been identified (Smith et al., 1997; NouroozZadeh et al., 1999; Lauderback et al., 2001; Halliwell, 2006; Dizdaroglu et al., 2015; Milne et al., 2015; Wang et al., 2015; Di Domenico et al., 2016, 2017; Dai et al., 2018; Ishii et al., 2018), but only a limited data on the usefulness of these biomarkers in the early detection of $\mathrm{AD}$ is available (GarciaBlanco et al., 2017). Several antioxidants have been proposed for ameliorating oxidative damage in humans and non-human models of AD (Butterfield and Halliwell, 2019). Among these, some are preventive while others are touted to have a curative effect in AD. A discussion on the rigor of the evidence favoring the purported antioxidants in preventing or treating human $\mathrm{AD}$ is scarce.

Therefore, our objective is to highlight potential oxidative markers that can be used for early diagnosis of human $\mathrm{AD}$ and to evaluate the evidence for the natural antioxidants currently proposed to prevent or treat AD in humans. Primary research on OS and antioxidants in the context of human MCI and/or AD was analyzed. The studies on early detection of $\mathrm{AD}$, preclinical $\mathrm{AD}$, or $\mathrm{MCI}$ in humans in terms of oxidative damage and the research on antioxidants useful in these conditions were selected for review. It should be noted that the animal studies, the discussion on effects of any non-dietary intervention like exercise on MCI/AD (Suridjan et al., 2017), trials on synthetic compounds with antioxidant anti-AD potential like statins (Chu et al., 2018), data on novel or synthetic antioxidant supplements for AD (Tadokoro et al., 2020), OS-biometal association in $\mathrm{MCI} / \mathrm{AD}$ (Balmus et al., 2017), and studies on patients with comorbidities (Zheng et al., 2016) were deemed outside the scope of this article.

\section{OXIDATIVE STRESS MARKERS FOR EARLY DETECTION OF AD}

Studies have reported various products derived from proteins, lipids, DNA, or RNA that indicate OS in the brain. For example, OS damage to the protein can be determined by measuring 3nitrotyrosine, protein carbonyls, methionine sulfoxide or highly reactive aldehydes; lipid damage by determining isoprostanes and lipid and cyclic peroxides; DNA damage by estimating 8hydroxy-deoxyguanosine $(8 \mathrm{OHdG})$; and RNA damage has been determined by measuring 8-hydroxyguanine (8OHG; Butterfield and Halliwell, 2019).

\section{Oxidative Damage to Proteins}

Elevated levels of protein carbonyls and 3-nitrotyrosine in the MCI lymphocyte mitochondria (Sultana et al., 2013) and in the frontal cortex (Ansari and Scheff, 2010) and hippocampus of MCI and AD (Scheff et al., 2016) indicate that OS damage to proteins is an early sign of $\mathrm{AD}$. Oxidative inactivation of several proteins in the hippocampus leads to the progression of AD from MCI (Butterfield et al., 2006a). The oxidatively modified proteins in the cerebrospinal fluid (CSF) of MCI, as determined by redox proteomics, remain oxidized in the disease progression to AD (Di Domenico et al., 2016). Both $\mathrm{MCI}$ and $\mathrm{AD}$ patients show increased plasma levels of advanced oxidation protein products (Chico et al., 2013). Increased carbonyl groups content in the plasma of early AD subjects have been reported (Puertas et al., 2012). Carbonyl proteins in the plasma can be roughly three times higher in MCI/AD relative to the age-matched healthy controls (Greilberger et al., 2010; Table 1).

The specificity of plasma carbonyl proteins is still questionable since one cannot differentiate between $\mathrm{AD}$ and other dementias like vascular dementia based on carbonyl proteins alone (Polidori et al., 2004). Likewise, caloric restriction itself reduces oxidative damage to the brain proteins, measured by protein carbonyl levels (Forster et al., 2000). Further investigations are warranted that record patient's dietary habits whilst evaluating the link between plasma carbonyl proteins and early AD.

\section{Role of Lipid Peroxidation}

The plasma, CSF, and urine of MCI subjects exhibit higher levels of isoprostane 8,12-iso-iPF(2alpha)-VI, a marker of in vivo lipid peroxidation, as compared to cognitively normal elderly controls (Pratico et al., 2002). Plasma and whole blood levels of thiobarbituric acid reactive substances, an index of lipid peroxidation, are likewise high in early $\mathrm{AD}$ (Puertas et al., 2012; Martinez de Toda et al., 2019). Lipid hydroperoxides are the unstable products of lipid peroxidation that undergo non-enzymatic decomposition to generate aldehydes like malondialdehyde (MDA) and 4-hydroxynonenal (4-HNE); latter form covalent adducts to alter physiological proteins. High serum hydroperoxide levels are associated with MCI and AD (Cervellati et al., 2013, 2014a). The OS detected in the serum (high hydroperoxides with low residual antioxidant power) is more pronounced in $\mathrm{MCI}$ and $\mathrm{AD}$ as compared to vascular dementia (Cervellati et al., 2014b; Table 1), highlighting the specificity of certain lipid peroxidation outcomes in early detection of AD.

Elevated levels of MDA and 4-HNE have been reported in the brains of subjects with MCI or early AD (Keller et al., 2005; Butterfield et al., 2006b; Greilberger et al., 2008; Reed et al., 2008; Lopez et al., 2013; Scheff et al., 2016). Mitochondria isolated from MCI lymphocytes show increased levels of HNE-bound proteins (Sultana et al., 2013). Plasma production of MDA shows a gradation: $\mathrm{AD}>\mathrm{MCI}>$ healthy controls (Torres et al., 2011) and blood MDA levels have been correlated with the progression of MCI into AD (Baldeiras et al., 2010; Table 1). It should be noted that covalent adducts of 4-HNE are elevated in the brain and body fluids of other neurodegenerative diseases as well including Parkinson's disease and amyotrophic lateral sclerosis (Di Domenico et al., 2017), necessitating future research on the patterns of MDA and 4-HNE that could distinguish $\mathrm{AD}$ from other dementias and neurodegenerative diseases.

The level of F2-isoprostanes, indicating lipid peroxidation, is enhanced in the brain and CSF of MCI and AD patients, but plasma and urinary isoprostanes are normal in $\mathrm{AD}$ (Markesbery et al., 2005; Irizarry et al., 2007). A prospective populationbased study failed to confirm the association between systemic isoprostanes and the risk of AD (Sundelöf et al., 2009). Despite being touted as "gold standard" biomarker of lipid peroxidation (Butterfield and Halliwell, 2019), the diagnostic 
TABLE 1 | Oxidative markers for early detection of Alzheimer's disease.

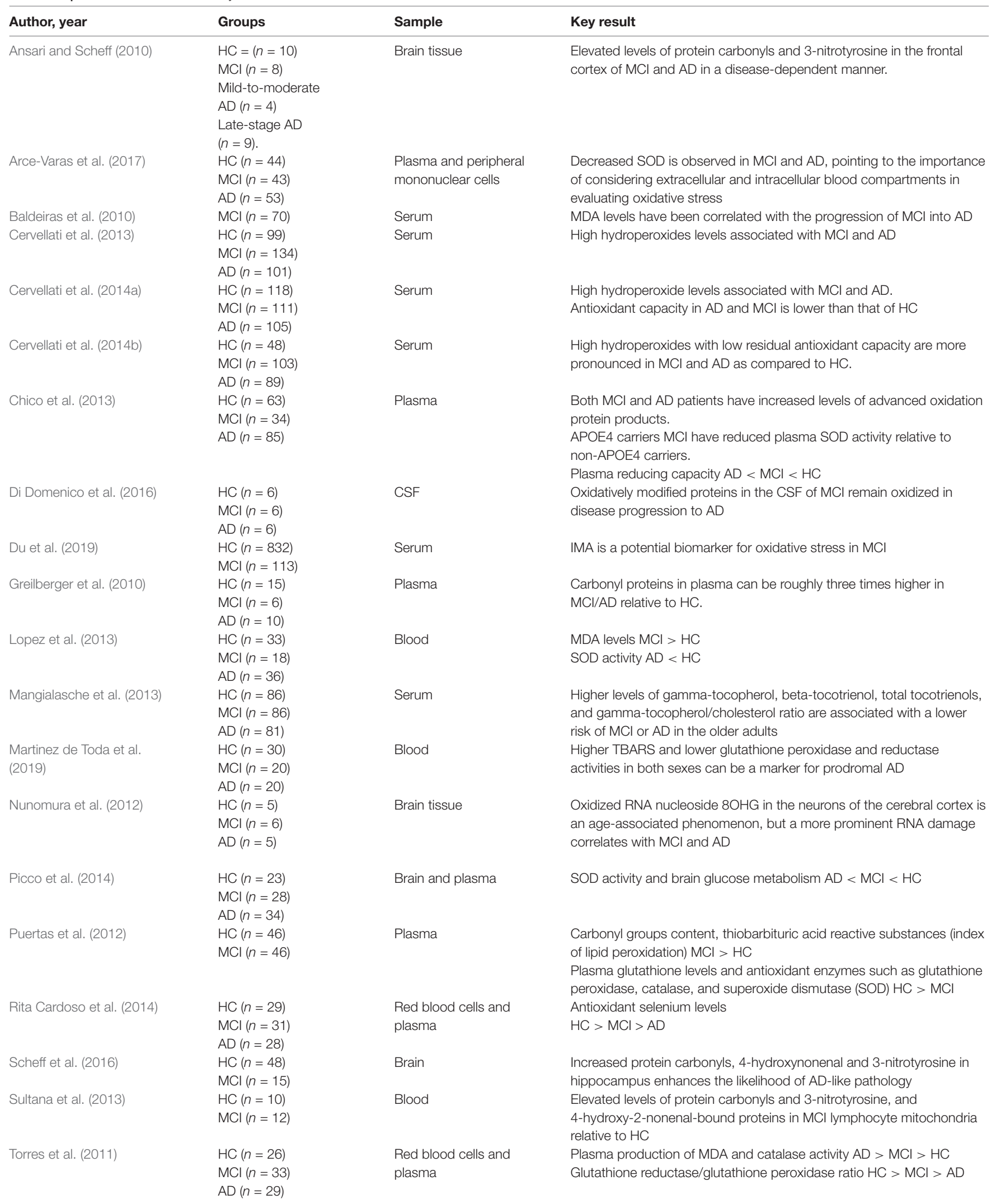

AD, Alzheimer's disease; APOE4, Apolipoprotein E4; CSF, Cerebrospinal fluid; HC, Healthy control with no cognitive impairment; IMA, Ischemia-modified albumin; MCI, Mild cognitive impairment; MDA, malondialdehyde; $8 O H G$, 8-hydroxyguanosine; SOD, superoxide dismutase; TBARS, thiobarbituric acid-reactive substances. 
use of isoprostanes is tricky because of their non-specificity: isoprostanes have been potential biomarkers for many diseases including obesity, genetic disorders and cancers (Irizarry et al., 2007; Milne et al., 2015).

\section{Oxidative Damage to Nucleic Acids}

Nucleic acid damage also occurs early in AD. Significantly elevated levels of $8 \mathrm{OHG}$ and 4,6-diamino-5formamidopyrimidine have been reported in the post-mortem MCI brains relative to the age-matched controls (Wang et al., 2006). Oxidized RNA nucleoside $8 \mathrm{OHG}$ in the neurons of the cerebral cortex is an age-associated phenomenon, but a more prominent RNA damage correlates with MCI and AD (Nunomura et al., 2012). Peripheral leukocytes from MCI and $\mathrm{AD}$ patients show enhanced oxidative DNA damage including higher amounts of oxidized purines and pyrimidines relative to the healthy controls (Migliore et al., 2005). Certain nuclear (but not mitochondrial) oxidative phosphorylation genes are upregulated in the hippocampus of MCI patients relative to both $\mathrm{AD}$ and normal controls (Mastroeni et al., 2017). What pattern of oxidative damage and gene expression can best distinguish $\mathrm{AD}$ at an early stage from other dementia is an open question.

\section{Reduced Antioxidant Defenses}

In addition to oxidative damage, reduced antioxidant defenses have been reported in MCI and early AD (Rinaldi et al., 2003; Baldeiras et al., 2010; Chico et al., 2013). Plasma glutathione levels and antioxidant enzymes such as glutathione peroxidase, catalase, and superoxide dismutase (SOD) are significantly decreased in early AD (Torres et al., 2011; Puertas et al., 2012). Apolipoprotein E4 (APOE4) is the major genetic risk factor in AD. The E4 carriers MCI exhibit significantly reduced plasma SOD activity relative to non-APOE4 carriers (Chico et al., 2013). Plasma SOD activity follows gradation: healthy controls > MCI > AD (Picco et al., 2014). Decreased SOD has also been reported in blood peripheral mononuclear cells of MCI and AD patients (Arce-Varas et al., 2017; Table 1). In other words, reduced antioxidant potential can be detected in both the extracellular and intracellular blood compartments.

Serum analysis of MCI and $\mathrm{AD}$ patients have revealed a low residual antioxidant power (Cervellati et al., 2014b). Albumin is considered a major endogenous antioxidant in serum because of its free radical-trapping ability. OS in MCI and $\mathrm{AD}$ can increase the serum levels of ischemia-modified albumin (IMA), a form of albumin in which the N-terminal is structurally changed (Du et al., 2019). The levels of selenium, an essential trace element, were found to be lower in both MCI and $\mathrm{AD}$ relative to the controls, but plasma selenium was the lowest in the AD group (Rita Cardoso et al., 2014; Table 1). Higher serum levels of gamma-tocopherol, beta-tocotrienol, total tocotrienols, and gamma-tocopherol/cholesterol ratio are associated with a lower risk of MCI or AD in the older adults (Mangialasche et al., 2013). Levels of 5-nitro-gamma-tocopherol, a marker of vitamin $\mathrm{E}$ damage, show a significant positive correlation with protein carbonyls, protein-conjugated HNE, and protein-bound 3-nitrotyrosine (Sultana et al., 2013) in MCI and AD (Table 1).
The limited specificity of OS and antioxidant markers must be kept in view. The serum, urine, or CSF concentrations of these biomolecules are associated with several cardiometabolic conditions (Vona et al., 2019) as well. Therefore, OS markers must always be combined with family history and other imaging techniques to detect $\mathrm{AD}$ at early stages.

\section{NATURAL ANTIOXIDANTS FOR ALZHEIMER'S DISEASE PREVENTION AND TREATMENT}

\section{Vitamins}

Plasma antioxidant defenses are depleted in MCI and AD (Rinaldi et al., 2003). So, antioxidant intake may be a reliable strategy to prevent or even reverse $\mathrm{MCI} / \mathrm{AD}$ symptoms. In this regard, vitamin $\mathrm{E}$ (tocopherols/tocotrienols) and vitamin $\mathrm{C}$ (ascorbate) is considered the scavenging and chain-breaking molecules called direct antioxidants (Mecocci and Polidori, 2012; Polidori and Nelles, 2014). Dietary vitamin E can dictate OS outcomes (Dong et al., 2018). Although vitamin E supplementation cannot stop the progression from MCI to $\mathrm{AD}$, it does delay the onset of $\mathrm{AD}$ symptoms (Dysken et al., 2014). Combining vitamin $\mathrm{E}$ with vitamin $\mathrm{C}$ is better at decreasing F2-isoprostane in the CSF in mild-to-moderate $\mathrm{AD}$ than the vitamin E alone (Galasko et al., 2012). The therapeutic importance of the latter observation is yet to be explored.

The risk of $\mathrm{AD}$ appears to be decreased in elderly subjects with high plasma levels of vitamin $\mathrm{E}$ (tocopherols and tocotrienols; Mecocci and Polidori, 2012; Polidori and Nelles, 2014), but this could be due to a good overall diet rather than vitamin $\mathrm{E}$ alone. Almond supplementation on an empty stomach has been found to enhanced memory in animal models of AD (Arslan et al., 2017; Batool et al., 2018). This can partly be explained by high amounts of antioxidants like vitamin $\mathrm{E}$ and selenium in almonds (Yada et al., 2011; Arslan et al., 2017). However, a clinical study reported that supplementation with vitamin $\mathrm{E}$ and selenium does not ameliorate human dementia (Kryscio et al., 2017). The result of this underpowered study (Kryscio et al., 2017) can be explained by the inclusion of only one gender (men), high loss to follow-up, and short exposure time.

\section{Polyphenols}

Polyphenolic agents, such as curcuminoids found in turmeric, work through multiple pathways and have shown improvements in AD symptoms in animal models (Ahmed and Gilani, 2009, 2014; Ahmed et al., 2014; Khalid et al., 2017), but results of human trials are conflicting (Chen et al., 2018). Gingko Biloba extract contains antioxidant flavonoids among other chemicals. Meta-analyses of human studies have shown promise in AD (Wang et al., 2010; Hashiguchi et al., 2015), but the results of Gingko biloba are far from conclusive (Vellas et al., 2012; Hashiguchi et al., 2015). Like curcumin, the neuroprotection by flavonoid-rich foods may not entirely be due to antioxidant effects since only a limited amount enters the brain. The additional mechanism behind neuroprotection includes flavonoid-induced improvement in brain vascular function (Schaffer and Halliwell, 2012). 
Catechins flavonoids are considered the active, therapeutic components of green tea. The ester of epigallocatechin and gallic acid called epigallocatechin-3-gallate (EGCG) is the main bioactive polyphenol in green tea extract that has neuroprotective effects partly owing to its antioxidant activities (Mandel et al., 2011; Mori et al., 2019). Green tea consumption seems to improve cognitive performance in the healthy (Kuriyama et al., 2006) as well as cognitively challenged elderly (Ide et al., 2014). However, the results of a long-term clinical trial of EGCG in the early stages of $\mathrm{AD}$ are yet to be published (ClinicalTrials.gov Identifier: NCT00951834). The EGCG dose and frequency needed for $\mathrm{AD}$ prevention and/or reversal must be explored further.

Other natural antioxidants tested extensively in animal models but only limitedly in humans for $\mathrm{AD}$ include: resveratrol, a polyphenol in grapes and red wine (Rege et al., 2014; Turner et al., 2015); blueberry extract (Papandreou et al., 2009); tannic acid (Mori et al., 2012); and lipoic acid (Siedlak et al., 2009).

\section{CONCLUSION}

Biomolecules predicting oxidative damage before the onset of clinical systems in $\mathrm{AD}$ can help in the diagnosis of this dreaded neurodegenerative disease. $\mathrm{AD}$ cannot be detected at an early stage based on oxidative markers alone because of the limited sensitivity and specificity of available options. Among the

\section{REFERENCES}

Ahmed, E. M., EL-Maraghy, S. A., Teleb, Z. A., and Shaheen, A. A. (2014). Pretreatment with turmeric modulates the inhibitory influence of cisplatin and paclitaxel on CYP2E1 and CYP3A1/2 in isolated rat hepatic microsomes. Chem. Biol. Interact. 220, 25-32. doi: 10.1016/j.cbi.2014.05.007

Ahmed, T., and Gilani, A. H. (2009). Inhibitory effect of curcuminoids on acetylcholinesterase activity and attenuation of scopolamine-induced amnesia may explain medicinal use of turmeric in Alzheimer's disease. Pharmacol. Biochem. Behav. 91, 554-559. doi: 10.1016/j.pbb.2008.09.010

Ahmed, T., and Gilani, A. H. (2014). Therapeutic potential of turmeric in Alzheimer's disease: curcumin or curcuminoids? Phytother. Res. 28, 517-525. doi: $10.1002 /$ ptr.5030

Ansari, M. A., and Scheff, S. W. (2010). Oxidative stress in the progression of Alzheimer disease in the frontal cortex. J. Neuropathol. Exp. Neurol. 69, 155-167. doi: 10.1097/nen.0b013e3181cb5af4

Arce-Varas, N., Abate, G., Prandelli, C., Martinez, C., Cuetos, F., Menendez, M., et al. (2017). Comparison of extracellular and intracellular blood compartments highlights redox alterations in Alzheimer's and mild cognitive impairment patients. Curr. Alzheimer Res. 14, 112-122. doi: $10.2174 / 1567205013666161010125413$

Arslan, J., Ahmed, T., and Gilani, A.-H. (2017). Soaked almonds exhibit vitamin e-dependent memory protective effect in rodent models. Int. J. Pharmacol. 13, 448-456. doi: 10.3923/ijp.2017.448.456

Baldeiras, I., Santana, I., Proenca, M. T., Garrucho, M. H., Pascoal, R., Rodrigues, A., et al. (2010). Oxidative damage and progression to Alzheimer's disease in patients with mild cognitive impairment. J. Alzheimers Dis. 21, 1165-1177. doi: 10.3233/jad-2010-091723

Balmus, I. M., Strungaru, S. A., Ciobica, A., Nicoara, M. N., Dobrin, R., Plavan, G., et al. (2017). Preliminary data on the interaction between some biometals and oxidative stress status in mild cognitive impairment and Alzheimer's disease patients. Oxid. Med. Cell. Longev. 2017:7156928. doi: 10.1155/2017/7156928

Batool, Z., Tabassum, S., Siddiqui, R. A., and Haider, S. (2018). Dietary supplementation of almond prevents oxidative stress by advocating non-invasive choices, lipid peroxidation (high serum peroxides) holds the most promise in the early detection of AD. It is unlikely, however, that a single non-invasive and cheap biomarker could detect $\mathrm{AD}$ at early stages. $\mathrm{AD}$ is a complex disease involving multiple pathways. OS is a part of normal aging, but a high OS can be one of the earliest signs of AD. The antioxidants offered to tackle oxidative damage in AD have limited efficacy partly because of the dose, duration, unbalanced monotherapy, and the presence of blood-brain-barrier that does not allow liberal amounts of antioxidants to enter the brain. By the time antioxidants are prescribed in humans, it is already too late. So, a balanced diet and lifestyle modifications can be the only long-term solution to prevent or reverse cognitive impairments associated with the heterogeneous disease that we call AD.

\section{AUTHOR CONTRIBUTIONS}

JA conceived the idea and wrote the first draft of the manuscript with equal inputs from $\mathrm{HJ}$ and $\mathrm{HQ}$.

\section{FUNDING}

The article processing charges were generously provided by Habib University, Karachi, Pakistan.

antioxidants and attenuates impaired aversive memory in male rats. Plant. Foods Hum. Nutr. 73, 7-12. doi: 10.1007/s11130-018-0655-4

Boasquivis, P. F., Silva, G. M. M., Paiva, F. A., Cavalcanti, R. M., Nunez, C. V. and de Paula Oliveira, R. (2018). Guarana (Paullinia cupana) extract protects caenorhabditis elegans models for alzheimer disease and huntington disease through activation of antioxidant and protein degradation pathways. Oxid. Med. Cell. Longev. 2018:9241308. doi: 10.1155/2018/9241308

Butterfield, D. A., and Halliwell, B. (2019). Oxidative stress, dysfunctional glucose metabolism and Alzheimer disease. Nat. Rev. Neurosci. 20, 148-160. doi: 10.1038/s41583-019-0132-6

Butterfield, D. A., Poon, H. F., St Clair, D., Keller, J. N., Pierce, W. M., Klein, J. B., et al. (2006a). Redox proteomics identification of oxidatively modified hippocampal proteins in mild cognitive impairment: insights into the development of Alzheimer's disease. Neurobiol. Dis. 22, 223-232. doi: 10.1016/j. nbd.2005.11.002

Butterfield, D. A., Reed, T., Perluigi, M., De Marco, C., Coccia, R., Cini, C., et al. (2006b). Elevated protein-bound levels of the lipid peroxidation product, 4hydroxy-2-nonenal, in brain from persons with mild cognitive impairment. Neurosci. Lett. 397, 170-173. doi: 10.1016/j.neulet.2005.12.017

Cervellati, C., Cremonini, E., Bosi, C., Magon, S., Zurlo, A., Bergamini, C. M., et al. (2013). Systemic oxidative stress in older patients with mild cognitive impairment or late onset alzheimer's disease. Curr. Alzheimer Res. 10, 365-372. doi: 10.2174/1567205011310040003

Cervellati, C., Romani, A., Seripa, D., Cremonini, E., Bosi, C., Magon, S., et al. (2014a). Systemic oxidative stress and conversion to dementia of elderly patients with mild cognitive impairment. Biomed. Res. Int. 2014:309507. doi: 10.14257/astl.2014.68.02

Cervellati, C., Romani, A., Seripa, D., Cremonini, E., Bosi, C., Magon, S., et al. (2014b). Oxidative balance, homocysteine and uric acid levels in older patients with Late onset alzheimer's disease or vascular dementia. J. Neurol. Sci. 337, 156-161. doi: 10.1016/j.jns.2013.11.041

Chen, M., Du, Z. Y., Zheng, X., Li, D. L., Zhou, R. P., and Zhang, K. (2018). Use of curcumin in diagnosis, prevention and treatment of Alzheimer's disease Neural Regen. Res. 13, 742-752. doi: 10.4103/1673-5374.230303 
Chico, L., Simoncini, C., Lo Gerfo, A., Rocchi, A., Petrozzi, L., Carlesi, C., et al. (2013). Oxidative stress and APO E polymorphisms in Alzheimer's disease and in mild cognitive impairment. Free Radic Res. 47, 569-576. doi: 10.3109/10715762.2013.804622

Chu, C. S., Tseng, P. T., Stubbs, B., Chen, T. Y., Tang, C. H., Li, D. J., et al. (2018). Use of statins and the risk of dementia and mild cognitive impairment: a systematic review and meta-analysis. Sci. Rep. 8:5804. doi: 10.1016/j.jalz.2018. 06.690

Dai, D. P., Gan, W., Hayakawa, H., Zhu, J. L., Zhang, X. Q., Hu, G. X., et al. (2018). Transcriptional mutagenesis mediated by 8-oxoG induces translational errors in mammalian cells. Proc. Natl. Acad. Sci. U S A 115, 4218-4222. doi: $10.1073 /$ pnas. 1718363115

Di Domenico, F., Pupo, G., Giraldo, E., Badìa, M.-C., Monllor, P., Lloret, A., et al. (2016). Oxidative signature of cerebrospinal fluid from mild cognitive impairment and Alzheimer disease patients. Free Radic. Biol. Med. 91, 1-9. doi: 10.1016/j.freeradbiomed.2015.12.004

Di Domenico, F., Tramutola, A., and Butterfield, D. A. (2017). Role of 4-hydroxy2-nonenal (HNE) in the pathogenesis of alzheimer disease and other selected age-related neurodegenerative disorders. Free Radic. Biol. Med. 111, 253-261. doi: 10.1016/j.freeradbiomed.2016.10.490

Dizdaroglu, M., Coskun, E., and Jaruga, P. (2015). Measurement of oxidatively induced DNA damage and its repair, by mass spectrometric techniques. Free Radic Res. 49, 525-548. doi: 10.3109/10715762.2015.1014814

Dong, S., Huang, X., Zhen, J., Van Halm-Lutterodt, N., Wang, J., Zhou, C., et al. (2018). Dietary vitamin E status dictates oxidative stress outcomes by modulating effects of fish oil supplementation in alzheimer disease model APPswe/PS1dE9 mice. Mol. Neurobiol. 55, 9204-9219. doi: 10.1007/s12035018-1060-6

Du, L., Ma, J., He, D., and Zhang, X. (2019). Serum ischaemia-modified albumin might be a potential biomarker for oxidative stress in amnestic mild cognitive impairment. Psychogeriatrics 19, 150-156. doi: 10.1111/psyg. 12377

Dysken, M. W., Sano, M., Asthana, S., Vertrees, J. E., Pallaki, M., Llorente, M., et al. (2014). Effect of vitamin E and memantine on functional decline in Alzheimer disease: the TEAM-AD VA cooperative randomized trial. JAMA 311, 33-44. doi: 10.1001/jama.2013.282834

Fattoretti, P., Malavolta, M., Fabbietti, P., Papa, R., Giacconi, R., Costarelli, L., et al. (2018). Oxidative stress in elderly with different cognitive status: my mind project. J. Alzheimers Dis. 63, 1405-1414. doi: 10.3233/jad-171117

Forster, M. J., Sohal, B. H., and Sohal, R. S. (2000). Reversible effects of long-term caloric restriction on protein oxidative damage. J. Gerontol. A Biol. Sci. Med. Sci. 55, B522-529. doi: 10.1093/gerona/55.11.b522

Galasko, D. R., Peskind, E., Clark, C. M., Quinn, J. F., Ringman, J. M., Jicha, G. A., et al. (2012). Antioxidants for Alzheimer disease: a randomized clinical trial with cerebrospinal fluid biomarker measures. Arch. Neurol. 69, 836-841. doi: 10.1001/archneurol.2012.85

Garcia-Blanco, A., Baquero, M., Vento, M., Gil, E., Bataller, L., and ChaferPericas, C. (2017). Potential oxidative stress biomarkers of mild cognitive impairment due to Alzheimer disease. J. Neurol. Sci. 373, 295-302. doi: 10.1016/j.jns.2017.01.020

Greilberger, J., Fuchs, D., Leblhuber, F., Greilberger, M., Wintersteiger, R., and Tafeit, E. (2010). Carbonyl proteins as a clinical marker in Alzheimer's disease and its relation to tryptophan degradation and immune activation. Clin. Lab 56, 441-448.

Greilberger, J., Koidl, C., Greilberger, M., Lamprecht, M., Schroecksnadel, K., Leblhuber, F., et al. (2008). Malondialdehyde, carbonyl proteins and albumin-disulphide as useful oxidative markers in mild cognitive impairment and Alzheimer's disease. Free Radic. Res. 42, 633-638. doi: 10.1080/10715760802255764

Halliwell, B. (2006). Oxidative stress and neurodegeneration: where are we now?. J. Neurochem. 97, 1634-1658. doi: 10.1111/j.1471-4159.2006.03907.x

Hashiguchi, M., Ohta, Y., Shimizu, M., Maruyama, J., and Mochizuki, M. (2015). Meta-analysis of the efficacy and safety of Ginkgo biloba extract for the treatment of dementia. J. Pharm. Health Care Sci. 1:14. doi: $10.1186 /$ isrctn02262139

Ide, K., Yamada, H., Takuma, N., Park, M., Wakamiya, N., Nakase, J., et al. (2014). Green tea consumption affects cognitive dysfunction in the elderly: a pilot study. Nutrients 6, 4032-4042. doi: 10.3390/nu6104032
Irizarry, M. C., Yao, Y., Hyman, B. T., Growdon, J. H., and Pratico, D. (2007). Plasma F2A isoprostane levels in Alzheimer's and Parkinson's disease. Neurodegener. Dis. 4, 403-405. doi: 10.1159/000107699

Ishii, T., Hayakawa, H., Igawa, T., Sekiguchi, T., and Sekiguchi, M. (2018). Specific binding of PCBP1 to heavily oxidized RNA to induce cell death. Proc. Natl. Acad. Sci. U S A 115, 6715-6720. doi: 10.1073/pnas.1806912115

Keller, J. N., Schmitt, F. A., Scheff, S. W., Ding, Q., Chen, Q., Butterfield, D. A., et al. (2005). Evidence of increased oxidative damage in subjects with mild cognitive impairment. Neurology 64, 1152-1156. doi: 10.1212/01.WNL.0000156156. 13641.BA

Khalid, A., Shakeel, R., Justin, S., Iqbal, G., Shah, S. A. A., Zahid, S., et al. (2017). Pharmacological effects of turmeric on learning, memory and expression of muscarinic receptor genes (M1, M3 and M5) in stress-induced mouse model. Curr. Drug Targets 18, 1545-1557. doi: 10.2174/138945011866617031 5120627

Kryscio, R. J., Abner, E. L., Caban-Holt, A., Lovell, M., Goodman, P., Darke, A. K., et al. (2017). Association of antioxidant supplement use and dementia in the prevention of Alzheimer's disease by vitamin $\mathrm{E}$ and selenium trial (PREADViSE). JAMA Neurol. 74, 567-573. doi: 10.1001/jamaneurol.2016.5778

Kuriyama, S., Hozawa, A., Ohmori, K., Shimazu, T., Matsui, T., Ebihara, S., et al. (2006). Green tea consumption and cognitive function: a crosssectional study from the Tsurugaya Project 1. Am. J. Clin. Nutr. 83, 355-361. doi: 10.1093/ajcn/83.2.355

Lauderback, C. M., Hackett, J. M., Huang, F. F., Keller, J. N., Szweda, L. I., Markesbery, W. R., et al. (2001). The glial glutamate transporter, GLT-1, is oxidatively modified by 4-hydroxy-2-nonenal in the Alzheimer's disease brain: the role of Abeta1-42. J. Neurochem. 78, 413-416. doi: 10.1046/j.1471-4159. 2001.00451.x

Lopez, N., Tormo, C., De Blas, I., Llinares, I., and Alom, J. (2013). Oxidative stress in Alzheimer's disease and mild cognitive impairment with high sensitivity and specificity. J. Alzheimers Dis. 33, 823-829. doi: 10.3233/jad-2012-121528

Mandel, S. A., Amit, T., Weinreb, O., and Youdim, M. B. (2011). Understanding the broad-spectrum neuroprotective action profile of green tea polyphenols in aging and neurodegenerative diseases. J. Alzheimers Dis. 25, 187-208. doi: 10.3233/jad-2011-101803

Mangialasche, F., Solomon, A., Kareholt, I., Hooshmand, B., Cecchetti, R., Fratiglioni, L., et al. (2013). Serum levels of vitamin E forms and risk of cognitive impairment in a Finnish cohort of older adults. Exp. Gerontol. 48, 1428-1435. doi: 10.1016/j.exger.2013.09.006

Markesbery, W. R., Kryscio, R. J., Lovell, M. A., and Morrow, J. D. (2005). Lipid peroxidation is an early event in the brain in amnestic mild cognitive impairment. Ann. Neurol. 58, 730-735. doi: 10.1002/ana.20629

Martinez de Toda, I., Miguelez, L., Vida, C., Carro, E., and De la Fuente, M. (2019). Altered redox state in whole blood cells from patients with mild cognitive impairment and Alzheimer's disease. J. Alzheimers Dis. 71, 153-163. doi: $10.3233 /$ jad-190198

Mastroeni, D., Khdour, O. M., Delvaux, E., Nolz, J., Olsen, G., Berchtold, N., et al. (2017). Nuclear but not mitochondrial-encoded oxidative phosphorylation genes are altered in aging, mild cognitive impairment, and Alzheimer's disease. Alzheimers Dement. 13, 510-519. doi: 10.1016/j.jalz.2016.09.003

Mecocci, P., and Polidori, M. C. (2012). Antioxidant clinical trials in mild cognitive impairment and Alzheimer's disease. Biochim. Biophys. Acta 1822, 631-638. doi: 10.1016/j.bbadis.2011.10.006

Migliore, L., Fontana, I., Trippi, F., Colognato, R., Coppede, F., Tognoni, G., et al. (2005). Oxidative DNA damage in peripheral leukocytes of mild cognitive impairment and AD patients. Neurobiol. Aging 26, 567-573. doi: 10.1016/j. neurobiolaging.2004.07.016

Milne, G. L., Dai, Q., and Roberts, L. J. 2nd. (2015). The isoprostanes-25 years later. Biochim. Biophys. Acta 1851, 433-445. doi: 10.1016/j.neurobiolaging. 2004.07.016

Mohamed, H. E., Abo, E. D. M., Mesbah, N. M., Saleh, S. M., Ali, A. A., and Sakr, A. T. (2018). Raspberry ketone preserved cholinergic activity and antioxidant defense in obesity induced Alzheimer disease in rats. Biomed Pharmacother 107, 1166-1174. doi: 10.1016/j.biopha.2018.08.034

Mori, T., Koyama, N., Tan, J., Segawa, T., Maeda, M., and Town, T. (2019). Combined treatment with the phenolics (-)-epigallocatechin-3-gallate and ferulic acid improves cognition and reduces Alzheimer-like pathology in mice. J. Biol. Chem. 294, 2714-2731. doi: 10.1074/jbc.ra118.004280 
Mori, T., Rezai-Zadeh, K., Koyama, N., Arendash, G. W., Yamaguchi, H., Kakuda, N., et al. (2012). Tannic acid is a natural beta-secretase inhibitor that prevents cognitive impairment and mitigates Alzheimer-like pathology in transgenic mice. J. Biol. Chem. 287, 6912-6927. doi: 10.1074/jbc.m111.294025

Nourooz-Zadeh, J., Liu, E. H., Yhlen, B., Änggåard, E. E., and Halliwell, B. (1999). F4-isoprostanes as specific marker of docosahexaenoic acid peroxidation in Alzheimer's disease. J. Neurochem. 72, 734-740. doi: 10.1046/j.1471-4159.1999. 0720734.x

Nunomura, A., Tamaoki, T., Motohashi, N., Nakamura, M., McKeel, D. W. Jr., Tabaton, M., et al. (2012). The earliest stage of cognitive impairment in transition from normal aging to Alzheimer disease is marked by prominent RNA oxidation in vulnerable neurons. J. Neuropathol. Exp. Neurol. 71, 233-241. doi: 10.1097/nen.0b013e318248e614

Papandreou, M. A., Dimakopoulou, A., Linardaki, Z. I., Cordopatis, P., KlimisZacas, D., Margarity, M., et al. (2009). Effect of a polyphenol-rich wild blueberry extract on cognitive performance of mice, brain antioxidant markers and acetylcholinesterase activity. Behav. Brain Res. 198, 352-358. doi: 10.1016/j. bbr.2008.11.013

Picco, A., Polidori, M. C., Ferrara, M., Cecchetti, R., Arnaldi, D., Baglioni, M., et al. (2014). Plasma antioxidants and brain glucose metabolism in elderly subjects with cognitive complaints. Eur. J. Nucl. Med. Mol. Imaging 41, 764-775. doi: 10.1007/s00259-013-2638-x

Polidori, M. C., Mattioli, P., Aldred, S., Cecchetti, R., Stahl, W., Griffiths, H., et al. (2004). Plasma antioxidant status, immunoglobulin g oxidation and lipid peroxidation in demented patients: relevance to Alzheimer disease and vascular dementia. Dement. Geriatr. Cogn. Disord. 18, 265-270. doi: 10.1159/000080027

Polidori, M. C., and Nelles, G. (2014). Antioxidant clinical trials in mild cognitive impairment and Alzheimer's disease-challenges and perspectives. Curr. Pharm. Des. 20, 3083-3092. doi: 10.2174/13816128113196660706

Popli, D., Anil, V., Subramanyam, A. B., M, N. N., V, R. R., Rao, S. N., et al. (2018). Endophyte fungi, Cladosporium species-mediated synthesis of silver nanoparticles possessing in vitro antioxidant, anti-diabetic and anti-Alzheimer activity. Artif. Cells Nanomed. Biotechnol. 46, 676-683. doi: 10.1080/21691401. 2018.1434188

Pratico, D., Clark, C. M., Liun, F., Rokach, J., Lee, V. Y., and Trojanowski, J. Q. (2002). Increase of brain oxidative stress in mild cognitive impairment: a possible predictor of Alzheimer disease. Arch. Neurol. 59, 972-976. doi: 10.1001/archneur.59.6.972

Puertas, M. C., Martinez-Martos, J. M., Cobo, M. P., Carrera, M. P., Mayas, M. D., and Ramirez-Exposito, M. J. (2012). Plasma oxidative stress parameters in men and women with early stage Alzheimer type dementia. Exp. Gerontol. 47, 625-630. doi: 10.1016/j.exger.2012.05.019

Reed, T., Perluigi, M., Sultana, R., Pierce, W. M., Klein, J. B., Turner, D. M., et al. (2008). Redox proteomic identification of 4-hydroxy-2-nonenal-modified brain proteins in amnestic mild cognitive impairment: insight into the role of lipid peroxidation in the progression and pathogenesis of Alzheimer's disease. Neurobiol. Dis. 30, 107-120. doi: 10.1016/j.nbd.2007.12.007

Rege, S. D., Geetha, T., Griffin, G. D., Broderick, T. L., and Babu, J. R. (2014). Neuroprotective effects of resveratrol in Alzheimer disease pathology. Front. Aging Neurosci. 6:218. doi: 10.3389/fnagi.2014.00218

Rinaldi, P., Polidori, M. C., Metastasio, A., Mariani, E., Mattioli, P., Cherubini, A., et al. (2003). Plasma antioxidants are similarly depleted in mild cognitive impairment and in Alzheimer's disease. Neurobiol. Aging 24, 915-919. doi: 10.1016/s0197-4580(03)00031-9

Rita Cardoso, B., Silva Bandeira, V., Jacob-Filho, W., and Franciscato Cozzolino, S. M. (2014). Selenium status in elderly: relation to cognitive decline. J. Trace Elem. Med. Biol. 28, 422-426. doi: 10.1016/j.jtemb.2014.08.009

Schaffer, S., and Halliwell, B. (2012). Do polyphenols enter the brain and does it matter? Some theoretical and practical considerations. Genes Nutr. 7, 99-109. doi: 10.1007/s12263-011-0255-5

Scheff, S. W., Ansari, M. A., and Mufson, E. J. (2016). Oxidative stress and hippocampal synaptic protein levels in elderly cognitively intact individuals with Alzheimer's disease pathology. Neurobiol. Aging 42, 1-12. doi: 10.1016/j. neurobiolaging.2016.02.030

Siedlak, S. L., Casadesus, G., Webber, K. M., Pappolla, M. A., Atwood, C. S., Smith, M. A., et al. (2009). Chronic antioxidant therapy reduces oxidative stress in a mouse model of Alzheimer's disease. Free Radic Res. 43, 156-164. doi: 10.1080/10715760802644694
Smith, M. A., Harris, P. L. R., Sayre, L. M., Beckman, J. S., and Perry, G. (1997). Widespread peroxynitrite-mediated damage in Alzheimer's disease. J. Neurosci. 17, 2653-2657. doi: 10.1523/jneurosci.17-08-02653.1997

Sultana, R., Baglioni, M., Cecchetti, R., Cai, J., Klein, J. B., Bastiani, P., et al. (2013). Lymphocyte mitochondria: toward identification of peripheral biomarkers in the progression of Alzheimer disease. Free Radic. Biol. Med. 65, 595-606. doi: 10.1016/j.freeradbiomed.2013.08.001

Sundelöf, J., Kilander, L., Helmersson, J., Larsson, A., Ronnemaa, E., Degerman-Gunnarsson, M., et al. (2009). Systemic tocopherols and F2-isoprostanes and the risk of Alzheimer's disease and dementia: a prospective population-based study. J. Alzheimers Dis. 18, 71-78. doi: 10.3233/jad-20091125

Suridjan, I., Herrmann, N., Adibfar, A., Saleem, M., Andreazza, A., Oh, P. I., et al. (2017). Lipid Peroxidation markers in coronary artery disease patients with possible vascular mild cognitive impairment. J. Alzheimers Dis. 58, 885-896. doi: 10.3233 /jad-161248

Tadokoro, K., Ohta, Y., Inufusa, H., Loon, A. F. N., and Abe, K. (2020). Prevention of cognitive decline in Alzheimer's disease by novel antioxidative supplements. Int. J. Mol. Sci. 21:1974. doi: 10.3390/ijms21061974

Thomas, K. R., Bangen, K. J., Weigand, A. J., Edmonds, E. C., Wong, C. G., Cooper, S., et al. (2020). Objective subtle cognitive difficulties predict future amyloid accumulation and neurodegeneration. Neurology 94, e397-e406. doi: 10.1212/WNL.0000000000008838

Torres, L. L., Quaglio, N. B., de Souza, G. T., Garcia, R. T., Dati, L. M., Moreira, W. L., et al. (2011). Peripheral oxidative stress biomarkers in mild cognitive impairment and Alzheimer's disease. J. Alzheimers Dis. 26, 59-68. doi: 10.3233/JAD-2011-110284

Turner, R. S., Thomas, R. G., Craft, S., van Dyck, C. H., Mintzer, J., Reynolds, B. A., et al. (2015). A randomized, double-blind, placebo-controlled trial of resveratrol for Alzheimer disease. Neurology 85, 1383-1391. doi: 10.1212/wnl. 0000000000002206

Vellas, B., Coley, N., Ousset, P. J., Berrut, G., Dartigues, J. F., Dubois, B., et al. (2012). Long-term use of standardised Ginkgo biloba extract for the prevention of Alzheimer's disease (GuidAge): a randomised placebocontrolled trial. Lancet Neurol. 11, 851-859. doi: 10.1016/s1474-4422(12) 70206-5

Vona, R., Gambardella, L., Cittadini, C., Straface, E., and Pietraforte, D. (2019). Biomarkers of oxidative stress in metabolic syndrome and associated diseases. Oxid. Med. Cell. Longev. 2019:8267234. doi: 10.1155/2019/8267234

Wang, J.-X., Gao, J., Ding, S.-L., Wang, K., Jiao, J.-Q., Wang, Y., et al. (2015). Oxidative modification of miR-184 enables it to target Bcl-xL and Bcl-w. Mol. cell 59, 50-61. doi: 10.1016/j.molcel.2015.05.003

Wang, J., Markesbery, W. R., and Lovell, M. A. (2006). Increased oxidative damage in nuclear and mitochondrial DNA in mild cognitive impairment. J. Neurochem. 96, 825-832. doi: 10.1111/j.1471-4159.2005.03615.x

Wang, B. S., Wang, H., Song, Y. Y., Qi, H., Rong, Z. X., Wang, B. S., et al. (2010). Effectiveness of standardized ginkgo biloba extract on cognitive symptoms of dementia with a six-month treatment: a bivariate random effect meta-analysis. Pharmacopsychiatry 43, 86-91. doi: 10.1055/s-0029-1242817

Yada, S., Lapsley, K., and Huang, G. (2011). A review of composition studies of cultivated almonds: macronutrients and micronutrients. J. Food Comp. Analy. 24, 469-480. doi: 10.1016/j.jfca.2011.01.007

Zheng, T., Qin, L., Chen, B., Hu, X., Zhang, X., Liu, Y., et al. (2016). Association of plasma DPP4 activity with mild cognitive impairment in elderly patients with type 2 diabetes: results from the GDMD study in china. Diabetes Care 39, 1594-1601. doi: $10.2337 / \mathrm{dc} 16-0316$

Conflict of Interest: The authors declare that the research was conducted in the absence of any commercial or financial relationships that could be construed as a potential conflict of interest.

Copyright (c) 2020 Arslan, Jamshed and Qureshi. This is an open-access article distributed under the terms of the Creative Commons Attribution License (CC BY). The use, distribution or reproduction in other forums is permitted, provided the original author(s) and the copyright owner(s) are credited and that the original publication in this journal is cited, in accordance with accepted academic practice. No use, distribution or reproduction is permitted which does not comply with these terms. 